Themed Issue: Drug Addiction - From Basic Research to Therapies

Guest Editors - Rao Rapaka and Wolfgang Sadée

\title{
New Paradigms and Tools in Drug Design for Pain and Addiction
}

Submitted: March 9, 2006; Accepted: April 13, 2006; Published: July 14, 2006

Victor J. Hruby, ${ }^{1,3}$ Frank Porreca, ${ }^{2}$ Henry I. Yamamura, ${ }^{2}$ Gordon Tollin,,${ }^{1,3}$ Richard S. Agnes, ${ }^{1}$ Yeon Sun Lee, ${ }^{1}$ Minying Cai, ${ }^{1}$ Isabel Alves, ${ }^{1,3}$ Scott Cowell, ${ }^{1}$ Eva Varga, ${ }^{2}$ Peg Davis, ${ }^{2}$ Zdzislaw Salamon, ${ }^{3}$ William Roeske, ${ }^{2}$

Todd Vanderah, ${ }^{2}$ and Josephine $\mathrm{Lai}^{2}$

${ }^{1}$ Department of Chemistry, University of Arizona, Tucson, AZ

${ }^{2}$ Department of Pharmacology, University of Arizona, Tucson, AZ

${ }^{3}$ Departments of Biochemistry and Molecular Biophysics, University of Arizona, Tucson, AZ

\section{AbSTRACT}

New modalities providing safe and effective treatment of pain, especially prolonged pathological pain, have not appeared despite much effort. In this mini-review/overview we suggest that new paradigms of drug design are required to counter the underlying changes that occur in the nervous system that may elicit chronic pain states. We illustrate this approach with the example of designing, in a single ligand, molecules that have agonist activity at $\mu$ and $\delta$ opioid receptors and antagonist activities at cholecystokinin (CCK) receptors. Our findings thus far provide evidence in support of this new approach to drug design. We also report on a new biophysical method, plasmon waveguide resonance (PWR) spectroscopy, which can provide new insights into information transduction in G-protein coupled receptors (GPCRs) as illustrated by the $\delta$ opioid receptor.

KEYWORDS: drug design, neuropathic pain, bifunctional ligands, plasmon waveguide resonance spectroscopy, GPCRs, opioid receptors, cholecystokinin receptors

\section{INTRODUCTION}

Despite much effort, medications providing effective and tolerable treatment of chronic abnormal pains such as neuropathic pain have not appeared in the past 2 decades. The reasons for this are multifaceted and involve cultural, political, economic, social, and scientific considerations. From a scientific perspective it has become increasingly clear that current methods of drug design ${ }^{1}$ are inadequate and require revision when considering the nonphysiological state of the nervous system, which is associated with chronic pain. ${ }^{2}$

Many recent studies ${ }^{3-5}$ have suggested that in neuropathic pain states adaptations occur in the central and peripheral nervous systems that may change the expected pain-relieving actions of analgesics such as morphine. An additional com-

Corresponding Author: Victor J. Hruby, Regents

Professor, Department of Chemistry, University of Arizona, Tucson, AZ 85721. Tel: (520) 621-6332;

Fax: (520) 621-8407; E-mail: hruby@u.arizona.edu plication is the recent understanding that in addition to their pain-relieving actions, opioids can elicit unexpected development of hyperalgesia, or an increase in sensitivity to normally noxious and also to nonnoxious stimuli, resulting in enhancement of pain. ${ }^{6,7}$ Adaptations that can occur in the nervous system in conditions of chronic pain include increases in the expression and activity of endogenous neurotransmitters, such as cholecystokinin (CCK), which may act both as pronociceptive substances and produce "anti-opioid" effects as well. ${ }^{8}$ Both of these actions will diminish the analgesic actions of opioids, reducing the expected therapeutic benefit of these drugs. In this article, we outline a new approach for designing drugs that will be effective in these pain states and illustrate this approach by designing single ligands that can act as both agonists at opioid receptors and antagonists at CCK receptors. Additionally, the possibility that opiate use may produce increased sensitivity to pain is an aspect of pain management that is now receiving considerable attention, as indicated by the spate of recent blinded clinical studies. Investigations performed with patients undergoing surgery showed that intraoperative opiate administration resulted in increased postoperative pain and increased the dose required for postoperative analgesics in order to achieve analgesia. ${ }^{9}$

Finally, we discuss a new biophysical method, plasmon waveguide resonance (PWR) spectroscopy that allows, for the first time, direct examination, in real time, of the structural changes that occur to G-protein coupled receptors (GPCRs) in model membrane bilayers when the receptor interacts with agonists, antagonists, and inverse agonists, and the effects on G-proteinreceptor interactions on these different receptor-occupied conformational states. These studies can be done without any spectroscopic labels, radioactive moieties, or other structure modifications that often can interfere with or change the nature of the interactions. Surprising results are obtained that suggest a major revision of current models of GPCR-mediated effects.

\section{MATERIALS AND METHODS}

\section{Peptide Synthesis}

Peptide synthesis of the ligands discussed here was accomplished by standard methods of solid phase peptide 
synthesis using the $\mathrm{N}^{\alpha}$-Fmoc strategy. ${ }^{10}$ The synthesized peptides were purified by gel filtration and preparative reverse-phase high-performance liquid chromatography (HPLC) generally using a gradient system composed of acetonitrile and $0.1 \%$ aqueous trifluoroacetic acid. Purity was assessed by thin layer chromatography in 3 solvent systems and by analytic HPLC. Further analysis of the structure was determined using high-resolution mass spectrometry and amino acid analysis, and by nuclear magnetic resonance spectroscopy in selected samples. The peptides generally were greater than $98 \%$ pure.

\section{Binding Assays}

Receptor binding affinities to the $\delta$ - and $\mu$-opioid receptors were performed with membrane preparations using methods previously reported. ${ }^{11}$ Binding affinities to the CCK receptors (CCK-1 and CCK-2) were made using stably transfected cell lines that express the human CCK-1 or CCK-2 receptors (the cDNA were gifts from Dr. Alan Kopin) using published methods that were recently published. Radiolabeled ligands used were $\left[{ }^{3} \mathrm{H}\right] \mathrm{c}\left[\mathrm{DPen},{ }^{2} \mathrm{DPen}^{5}\right]-$ enkephalin (DPDPE) or $\left[{ }^{3} \mathrm{H}\right]$-deltorphin II for the $\delta$ opioid receptor, D-Phe-c[Cys-Tyr-D-Trp-Arg-Thr-Pen]-Thr-NH ${ }_{2}$ $\left(\left[{ }^{3} \mathrm{H}\right] \mathrm{CTAP}\right)$ or $\left[\mathrm{D}-\mathrm{Ala}^{2}, \mathrm{Gly}-\mathrm{OH}^{5}\right]$ enkephalin $\left(\left[{ }^{3} \mathrm{H}\right] \mathrm{DAMGO}\right)$ for the $\mu$-opioid receptor, and $\left[{ }^{3} \mathrm{H}\right] \mathrm{CCK}-8$ (sulfated) for the CCK-1 and CCK-2 receptors. Multiple assays were performed for each ligand reported, and the results were analyzed statistically.

\section{Bioassay}

In vitro functional bioassays were determined using the guinea pig ileum (GPI, $\mu$ ), mouse vas deferens (MVD, $\delta$ ), and the unstimulated GPI/LMMP (CCK receptor) (versus the sulfated CCK-8 for antagonist activity) as described previously. ${ }^{12}$ Multiple assays were performed for each ligand, and the results were analyzed statistically.

\section{Plasmon-Waveguide Resonance Spectroscopy}

PWR spectra were obtained by resonance excitation of conduction electron oscillations (plasmons) by polarized light from a CW laser at wavelengths of 632.8 or $543.5 \mathrm{~nm}$ incident on the back surface of a thin metal film (Ag) coated by a layer of $\mathrm{SiO}_{2}$ deposited on a glass prism, ${ }^{13,14}$ using a Proterion Corp (Piscataway, NJ) instrument that had a spectral resolution of 1 millidegree (mdeg). The sample to be analyzed (a solid-supported lipid bilayer membrane) was immobilized on the resonator $\mathrm{SiO}_{2}$ surface and placed in contact with an aqueous medium to which proteins and ligands could be introduced. The deposited molecules (eg, bilayer, GPCRs, G-proteins) change the resonance charac- teristics and thereby influence the plasmon spectra. The PWR spectra, which are plots of reflected light intensity versus the incident angle, can be obtained with light whose electric vector is either parallel or perpendicular to the plane of the resonator surface ( $s$ - or $p$ - polarization, respectively). From these spectra 2 refractive index values $\left(n_{s}\right.$ and $\left.n_{p}\right)$ as well as the sample thickness $(t)$ can be determined. This provides information about changes in the mass density, structural asymmetry, and molecular orientation that results from the molecular interactions occurring at the resonator surface. ${ }^{15,16}$

\section{Receptor Purification and Characterization; Incorporation of hDOR Into a Lipid Bilayer by Detergent Dilution Followed by Ligand or G-Protein Addition}

A fully functional human $\delta$ opioid receptor (hDOR) with a Myc and His tag was stably transfected into a Chinese hamster ovary cell line (CHO-K1) and was solubilized and purified as previously reported. ${ }^{16,17}$ For studies in which the receptors were prebound with ligand (to study G-protein interactions with the liganded receptor), the solubilized purified receptors were incubated with saturating amounts of a peptide agonist (DPDPE), a nonpeptide agonist (SNC80), or an antagonist (Naltrindole, NTI) for 1 to 2 hours at $4{ }^{\circ} \mathrm{C}$ prior to introduction into the PWR cell that contained a previously prepared lipid bilayer, which was assembled as previously reported. ${ }^{16}$ This bilayer is formed within the orifice of a Teflon sheet on the PWR cell surface that separates the resonator from the aqueous medium. This provides a lipid bilayer with an annulus of lipid at the borders of the orifice, which allows lipid molecules to move into and out of the bilayer in response to protein insertion and/or changes in the protein conformation. In general, the lipid bilayers consisted of egg phosphatidylcholine (PC) and 1-palmitoyl2-oleyl-sn-glycero-3-phosphoglycerol (Avanti Polar Lipids, Alabaster, AL) $(75 / 25 \mathrm{~mol} / \mathrm{mol})$ prepared as previously reported. ${ }^{17}$ The receptors (either unoccupied or ligand occupied) were incorporated into the lipid bilayer by introducing the purified detergent-solubilized hDOR receptor in $30 \mathrm{mM}$ octyl glucoside-containing buffer into the aqueous compartment of the resonator prism under conditions that dilute the detergent to below the critical micelle concentration (CMC), which allows the receptor protein to spontaneously insert into the lipid bilayer. Based on a variety of control experiments, the evidence suggests that the receptor molecules insert bidirectionally into the lipid bilayer; that is, with the extracellular side facing both the silica surface (this allows examination of G-protein interactions with the receptor) and the aqueous compartment (this allows examination of ligand-receptor interactions). G-proteins examined include mixtures of $G_{\alpha o}, G_{\alpha i 1}$, $G_{\alpha i 2}$, and $G_{\alpha i 3}$ (or pure single $G_{\alpha}$ subunits) and a $\beta \gamma$ subunit 
complex (a mixture of the different $\beta \gamma$ subtypes present in the brain - both obtained from Calbiochem, EMD Biosciences, La Jolla, CA). Aliquots of ligand or G-protein solutions were incrementally added to increase their concentration so as to effectively examine the dose-response of these molecules. For the GTP $\gamma \mathrm{S}$ (Sigma, St Louis, MO.) binding studies, the G-protein-receptor complex formation was at full saturation before GTP $\gamma \mathrm{S}$ was added (again incrementally). In these experiments, the changes in the spectra were monitored using both $s$ - and $p$ - polarized light. From these experiments, hyperbolic saturation curves corresponding to a plot of the concentration of the ligand (or G-protein) added versus the resonance position angle (in mdeg) can be obtained to provide $\mathrm{K}_{\mathrm{D}}$ values using standard curve fitting procedures.

\section{RESULTS AND DISCUSSION}

As discussed above, our analysis of the changes in the expression of neurotransmitters and their receptors that accompany the development of neuropathic pain and prolonged pain of various origins suggested to us that the design of a single ligand that had agonist activities at both $\delta$ and $\mu$ opioid receptors, and antagonist activity at CCK-1 and especially CCK-2 receptors, would provide a ligand that could directly address the changes in gene expression in the brain and spinal cord that accompany these pain states. Two specific approaches to the design of such ligands were considered: (1) development of a single ligand with overlapping pharmacophores for the opioid receptors and the CCK receptors, and (2) development of a single ligand that possessed the agonist pharmacophore for the $\mu$ and $\delta$ opioid receptors, and the antagonist pharmacophore for the CCK-1 and CCK-2 receptors joined together by a spacer. This latter approach, though successfully pursued, will not be further discussed here. The idea of developing a peptide or peptidomimetic ligand, which possesses affinity for both opioid and CCK receptors in a single molecule rather than in 2 separate molecules, was chosen for several reasons: (1) economy of structure especially when using the concept of overlapping pharmacophores in design, (2) development of a single moiety that would have a single mode of delivery, transport, metabolism, and biodistribution and a single toxicity (such a molecule would more easily obtain approval as a new drug by the Food and Drug Administration [FDA]), and (3) an opportunity to evaluate a new approach to drug design for disease states in which changes in gene expression are believed to have occurred and are important components of the disease state. If successful, we believe this approach can be applied to many other diseases such as cancer and diabetes.

In previous research directed to obtaining analogs of CCK8 with selectivity for the CCK-2 (or CCK-1) receptor, we obtained a ligand we designated as SNF-9007 (H-Asp-TyrD-Phe-Gly-Trp-NMeNle-Asp-Phe- $\mathrm{NH}_{2}$, Figure 1), which was highly potent and selective for the CCK-2 receptor ${ }^{18}$ but which had weak agonist activity at the $\delta$ and $\mu$ opioid receptors. ${ }^{18}$ Furthermore, we noticed, based on our modeling studies of the highly $\delta$ opioid selective cyclic enkephalin analog DPDPE 19 and of the CCK-8 structure, that they possessed similar topographical 3-dimensional structures, especially in the placement of critical aromatic residues important to both pharmacophores (Figure 2)..$^{20,21}$ Further modeling suggested that the 2 pharmacophores (DPDPE and CCK-8) could be overlapped in a single structure such as SNF-9007 (Figure 1). As outlined below we felt that further modification in such a structure could provide a single ligand with the desired biological activity profile.

\section{Structure-Activity Studies}

Our first goal was to convert SNF-9007 into a ligand with higher binding affinities and agonist activities at the $\delta$ and $\mu$ opioid receptors. Since the amino terminal Asp residue in SNF-9007 is detrimental to opioid receptor molecular recognition, and not essential for CCK receptor binding, we removed it and obtained compound $\mathbf{1}$ (Table 1), which had much improved affinity ( $\sim 0$-fold) for both the $\delta\left(\mathrm{K}_{\mathrm{i}}=\right.$ $6.8 \mathrm{nM})$ and $\mu\left(\mathrm{K}_{\mathrm{i}}=136 \mathrm{nM}\right)$ receptors. We then further improved the opioid binding affinity of 1 by replacing the $\mathrm{D}-\mathrm{Phe}^{2}$ residue with other $\mathrm{D}$-amino acid residues known to produce potent opioid ligands: (A) D-Ala in 2; (B) D-Nle in 3; and (C) Gly in 4. Significant improvements in binding affinity were seen for both $\mathbf{2}$ and $\mathbf{3}$ (Table 1), but surprisingly $\mathbf{4}$ had considerably reduced potency. Since enkephalin itself has a Gly in position 2, the reason for the large loss in binding affinity of $\mathbf{4}$ for opioid receptors is not clear.

It should be noted that the binding affinities of analogs 1 to 4 for the CCK-1 and CCK-2 receptors were largely unchanged by these modifications to the $\mathrm{N}$-terminal dipeptide residues of SNF-9007. Thus, we next sought to improve the binding of SNF-9007 for the CCK-1 receptor in particular to obtain a ligand with more balanced binding affinities for the 2 CCK receptors. As shown in Table 2, this was accomplished by using 1 (Table 1) as the starting ligand, and substituting the N-MeNle ${ }^{5}$ residue with a Nle residue, which was known from our previous studies of $\mathrm{CCK}^{22}$ to

\section{CCK PHARMACOPHORE}

\section{SNF-9007: Asp-Tyr-D-Phe-Gly-Trp-NMeNle-Asp-Phe-NH ${ }_{2}$}

OPIOID PHARMACOPHORE

Figure 1. Design of a single molecule with overlapping pharmacophores for opioid and CCK receptors. 

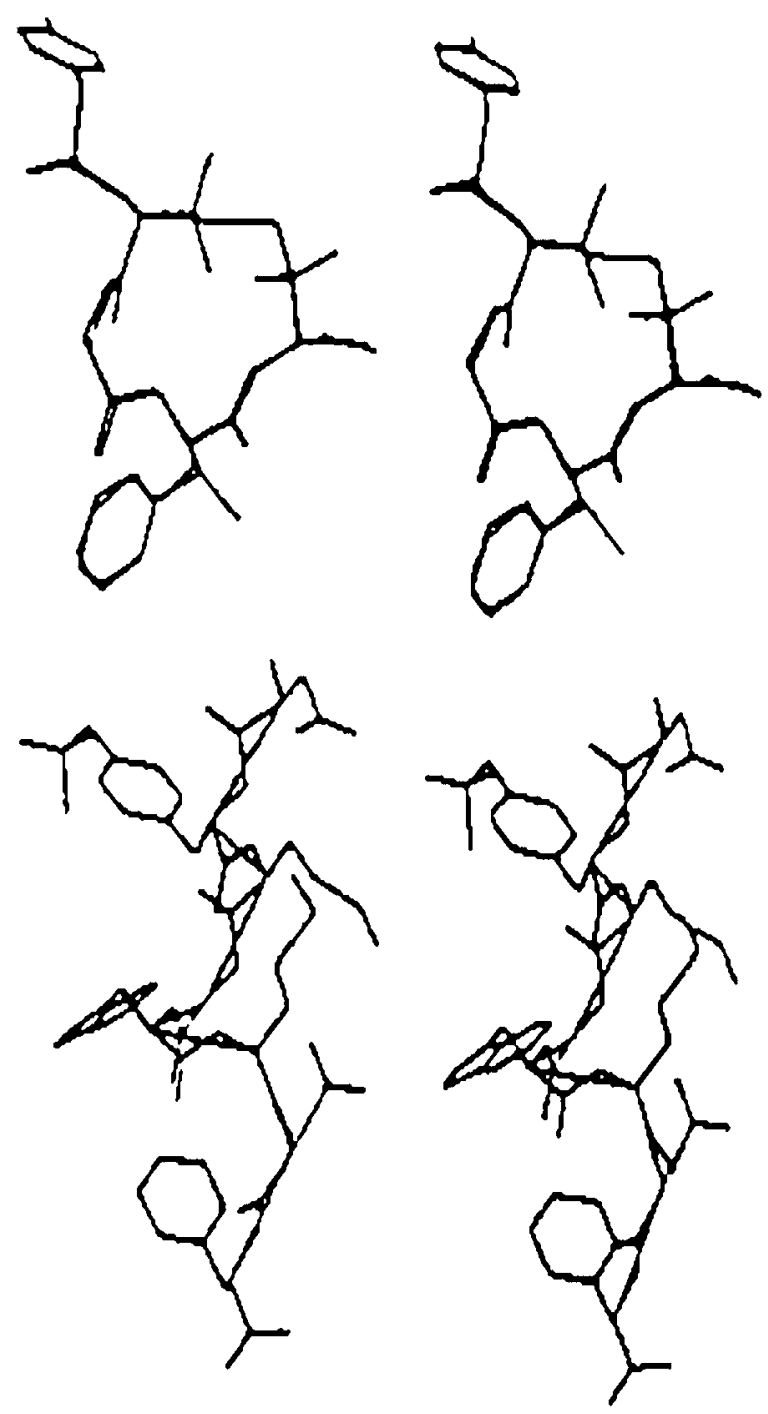

Figure 2. Similarities between the conformations of DPDPE (top) and $\mathrm{CCK}_{8}$ (bottom) shown in stereoview.

give ligands with more balanced CCK-1 and CCK-2 binding affinities. In addition we put a D-Phe (5) or a D-Ala (6) or a $\mathrm{D}-\mathrm{Nle}^{2}$ residue in position 2 (Table 2 ). In general, these modifications led to increased binding affinities for the CCK-1 receptor (90-fold for 5, 2-fold for 6, and 900-fold for 7), although with some decrease in binding affinities for the CCK-2 receptor. Most important, 7 was found to have very balanced binding affinity for both the CCK-1 and CCK-2 receptors. High affinity binding was retained for the $\mu$ and $\delta$ receptors as well.

Finally, we converted the analogs to ligands, which would be expected to have antagonist activity at CCK receptors (Table 3). It is well known from previous structure-activity relationships (SAR) studies with both CCK peptides and peptidomimetics that conversion of the L-Trp in CCK analogs to a D-Trp leads to compounds that are antagonists at CCK receptors. Hence, starting with 1 we replaced the L-Trp residue with a D-Trp residue to give 8 (Table 3), and
Table 1. Increasing the Binding Affinity at Opioid Receptors by Modifying SNF-9007*

\begin{tabular}{|c|c|c|c|c|}
\hline \multirow[b]{2}{*}{ Compound } & \multicolumn{2}{|c|}{$\begin{array}{l}\text { Opioid, } \\
\mathbf{K}_{\mathrm{i}}(\mathbf{n M} \mathbf{M})\end{array}$} & \multicolumn{2}{|c|}{$\begin{array}{c}\mathrm{CCK}, \\
\mathbf{K}_{\mathbf{i}}(\mathbf{n M})\end{array}$} \\
\hline & $\delta \dagger$ & $\mu+$ & CCK-1§ & $\overline{C C K-2 \S}$ \\
\hline $\begin{array}{l}\text { H-Asp-Tyr-D-Phe-Gly- } \\
\text { Trp-NMeNle-Asp-Phe-NH } \\
\text { (SNF-9007) }\end{array}$ & 250 & 5200 & 3300 & 2.1 \\
\hline $\begin{array}{l}\text { 1. H-Tyr-D-Phe-Gly-Trp- } \\
\text { NMeNle-Asp-Phe-NH } 2\end{array}$ & 6.8 & 136 & 10000 & 2.1 \\
\hline $\begin{array}{l}\text { 2. H-Tyr-D-Ala-Gly-Trp- } \\
\text { NMeNle-Asp-Phe-NH2 }\end{array}$ & 14 & 46 & 5700 & 2.1 \\
\hline $\begin{array}{l}\text { 3. H-Tyr-D-Nle-Gly-Trp- } \\
\text { NMeNle-Asp-Phe-NH2 }\end{array}$ & 1.6 & 25 & 3900 & 0.60 \\
\hline $\begin{array}{l}\text { 4. H-Tyr-Gly-Gly-Trp- } \\
\text { NMeNle-Asp-Phe-NH} 2\end{array}$ & 2010 & 610 & 870 & 1.3 \\
\hline
\end{tabular}

we also made an analog with a D-Ala ${ }^{2}$ residue (9, Table 3$)$. In both cases, analogs with potent binding affinities for the $\delta, \mu$, and CCK-2 receptors were obtained, and for 9 at the CCK-1 receptor as well. Of surprise, 8 still had weak affinity for the CCK-1 receptor, presumably because of the presence of a N-MeNle ${ }^{5}$ residue (although 9 also had this residue, it had high affinity for the CCK-1 receptor). As expected, 8 and 9 were antagonists at the CCK receptors (data not shown).

Finally, we examined the design of cyclic ligands related to the linear ligands discussed above. The linear analogs were

Table 2. SAR Studies to Balance the Selectivity for CCK-1 and CCK-2 Receptors*

\begin{tabular}{|c|c|c|c|c|}
\hline \multirow[b]{2}{*}{ Compound } & \multicolumn{2}{|c|}{$\mathbf{K}_{\mathrm{i}}(\mathbf{n M})$} & \multicolumn{2}{|c|}{$\mathbf{K}_{\mathrm{i}}(\mathbf{n M})$} \\
\hline & $\delta \dagger$ & $\mu$ & CCK-1§ & CCK-2§ \\
\hline $\begin{array}{l}\text { 1. H-Tyr-D-Phe-Gly-Trp- } \\
\text { NMeNle-Asp-Phe-NH2 }\end{array}$ & 6.8 & 136 & 10000 & 2.1 \\
\hline $\begin{array}{l}\text { 5. H-Tyr-D-Phe-Gly-Trp- } \\
\text { Nle-Asp-Phe-NH} 2\end{array}$ & 0.42 & 80 & 116 & 8.1 \\
\hline $\begin{array}{l}\text { 6. H-Tyr-D-Ala-Gly-Trp- } \\
\text { Nle-Asp-Phe-NH}{ }_{2}\end{array}$ & 39.1 & 3.3 & 5700 & 146 \\
\hline $\begin{array}{l}\text { 7. H-Tyr-D-Nle-Gly-Trp- } \\
\text { Nle-Asp-Phe-NH }{ }_{2}\end{array}$ & 2.9 & 27 & 11.2 & 15.8 \\
\hline
\end{tabular}

*CCK indicates cholecystokinin.

$\uparrow$ Competitive binding assay versus $\left[{ }^{3} \mathrm{H}\right] \mathrm{DPDPE}$.

†Competitive binding assay versus DAMGO.

$\S$ Competitive binding assay versus $\left[{ }^{3} \mathrm{H}\right] \mathrm{CCK}-8$. 
The AAPS Journal 2006; 8 (3) Article 53 (http://www.aapsj.org).

Table 3. Conversion to High-Affinity CCK Antagonist Activity*

\begin{tabular}{|c|c|c|c|c|}
\hline \multirow[b]{2}{*}[D-Trp^{4}]{ Analogues } & \multicolumn{2}{|c|}{$\begin{array}{l}\text { Opioid, } \\
K_{i}(n M)\end{array}$} & \multicolumn{2}{|c|}{$\begin{array}{c}\text { CCK, } \\
\mathbf{K}_{\mathbf{i}}(\mathbf{n M})\end{array}$} \\
\hline & $\delta \dagger$ & $\mu \neq$ & CCK-1§ & CCK-2§ \\
\hline $\begin{array}{l}\text { 1. H-Tyr-D-Phe- } \\
\text { Gly-Trp-NMeNle- } \\
\text { Asp-Phe-NH2 }\end{array}$ & 22 & 2.5 & 10000 & 2.1 \\
\hline $\begin{array}{l}\text { 8. H-Tyr-D-Phe- } \\
\text { Gly-D-Trp-NMeNle- } \\
\text { Asp-Phe-NH } 2\end{array}$ & 0.55 & 5.7 & 1080 & 1.6 \\
\hline $\begin{array}{l}\text { 9. H-Tyr-D-Ala- } \\
\text { Gly-D-Trp-NMeNle- } \\
\text { Asp-Phe-NH }{ }_{2}\end{array}$ & 1.9 & 20 & 32 & 1.3 \\
\hline $\begin{array}{l}\text { *CCK indicates cholecysto } \\
\text { †Competitive binding assay } \\
\text { +Competitive binding assay } \\
\text { \$Competitive binding assay }\end{array}$ & $\begin{array}{l}\text { kinin. } \\
\text { versus } \\
\text { versus } \\
\text { versus }\end{array}$ & $\begin{array}{l}\text { I]DPI } \\
\mathrm{MG} \\
\mathrm{I}] \mathrm{CCl}\end{array}$ & & \\
\hline
\end{tabular}

converted to cyclic analogs using a rational approach for making cyclic analogs from linear analogs by topographical modification and cyclization. ${ }^{23,24}$ In this case, we cyclized using structural modifications at positions 2 and 5 of the linear analogs discussed above. Both cyclic disulfide and cyclic lactam analogs were examined. Here we will report on our work with cyclic disulfides. In this approach we substituted position 2 with either D-Cys or D-Pen, whereas in position 5 we substituted with either D-Cys, Cys, or Pen (Table 4). Based on previous studies of cyclic opioid ligands based on DPDPE, which were extended at the C-terminal, ${ }^{25,26}$ it was anticipated that an L-Cys or L-Pen residue in the analogs would lead to higher affinity analogs on opioid receptors. As shown in Table 4 this turned out to be the case at the $\delta$ receptor $(13$ and 14 versus 15,16 , and 17) but not at the $\mu$ receptor, although $\mathbf{1 5}$ had the highest affinity at both the $\delta$ and $\mu$ receptors as expected. All of the cyclic disulfides had good to very good antagonist activities at the CCK receptors (Table 4).

In preliminary studies we have examined whether these ligands have binding affinity and, most important, in vivo activity in animal models of neuropathic pain and antiallodynic effects. Using the linear analog RSA 601 (H-TyrD-Phe-Glu-D-Trp-NMeNle-Asp-Phe- $\mathrm{NH}_{2}$ ) we have found that these compounds demonstrate dose-dependent activity using a descending facilitation animal pain model for neuropathic pain and in an in vivo anti-allodynic assay. Further studies are in progress to confirm these findings. However, it does appear that as predicted by our basic working hypothesis, ligands with the novel biological activities profiles of our new ligands can indeed provide for the first time ligands that are actually effective for neuropathic pain and allodynia. Studies are continuing to further expand on this model.
Table 4. Conformational Constraint With Disulfide Cyclization*

\begin{tabular}{|c|c|c|c|}
\hline \multirow{3}{*}{$\frac{\text { Cyclic Disulfide Analogues }}{\text { 7. H-Tyr-D-Nle-Gly- }}$} & \multicolumn{2}{|c|}{$\begin{array}{c}\text { Opioid } \\
\text { Agonist (nM) }\end{array}$} & $\begin{array}{c}\text { CCK } \\
\text { Antagonist }^{\S}(\mathbf{n M})\end{array}$ \\
\hline & \multicolumn{2}{|c|}{$\operatorname{MVD}(\delta)^{\dagger}$} & \multirow{2}{*}{$\frac{\mathbf{G P I}(\boldsymbol{\mu})^{\dagger}}{192}$} \\
\hline & 22.7 & 206 & \\
\hline $\begin{array}{l}\text { 13. H-Tyr-D-Cys-Gly- } \\
\text { Trp-D-Cys-Asp-Phe-NH }{ }_{2}\end{array}$ & 84 & 182 & 37.8 \\
\hline $\begin{array}{l}\text { 14. H-Tyr-c[D-Cys-Gly- } \\
\text { Trp-D-Cys]-Asp-Phe-NH }{ }_{2}\end{array}$ & 119 & 282 & 23 \\
\hline $\begin{array}{l}\text { 15. H-Tyr-c[D-Cys-Gly- } \\
\text { Trp-Cys]-Asp-Phe-NH} 2\end{array}$ & 0.45 & 63 & 7.6 \\
\hline $\begin{array}{l}\text { 16. H-Tyr-c[D-Pen-Gly- } \\
\text { Trp-Cys]-Asp-Phe-NH} 2\end{array}$ & 9.5 & 151 & 19 \\
\hline $\begin{array}{l}\text { 17. H-Tyr-c[D-Cys-Gly- } \\
\text { Trp-Pen]-Asp-Phe-NH } 2\end{array}$ & 15 & 290 & 24 \\
\hline $\begin{array}{l}\text { *CCK indicates cholecystokinir } \\
\dagger \text { Functional assay at mouse vas } \\
\text { †Functional assay at guinea pig } \\
\S \text { Competitive binding assay at } \\
\text { with myeuteric plexus (GPI/LM }\end{array}$ & $\begin{array}{l}\text { eferens }( \\
\text { eum }(\mu) \text {. } \\
\text { guinea } \\
\text { IP). }\end{array}$ & leu & longitudinal muscle \\
\hline
\end{tabular}

\section{Use of a Novel Biophysical Method to Directly Examine Structural Changes of GPCRs in Membrane Bilayers}

Efforts to examine directly the structural properties of integral membrane proteins such as GPCRs have been hampered by their intrinsic properties in the bilayers in which they are located in vivo, including (1) their relatively low abundance, (2) the difficulties in solubilizing them in a biologically active state, (3) their anisotropic properties in the bilayers, (4) the difficulty in crystallizing them so as to obtain high resolution structures, (5) the complexity of their molecular interactions (ligands, the trimeric G-proteins), and (6) the need to use radiolabels or even more problematic fluorescent probes to examine these interactions.

Here we report on a new method, PWR spectroscopy, which can overcome all of these difficulties. The method uses resonant excitation by light of plasmons, which are electronic oscillations, in a thin metal film (eg, silver) coated with a thicker dielectric layer (in our case silica), which is deposited on the surface of a prism. This setup generates a surfacelocalized evanescent electromagnetic field at the interface of the coated prism and the external aqueous medium. In this way, the optical properties of materials immobilized at this surface including lipid bilayers, GPCRs in the bilayers, the interactions of the GPCRs with their cognate ligands, and interactions with their G-proteins can be probed. This allows for the characterization of thermodynamic, kinetic, and structural properties and features of a wide variety of biomembrane systems (see references 12-16 for details of the instrumentation and its applications to anisotropic 
structural analysis). Most important, this method can be done with a very high degree of sensitivity (femtomole quantities of immobilized receptor, for example) and without the need for any labels or other structural modifications. For example, the kinetics and thermodynamics of ligand binding can be examined directly, and insights into the conformational/structural changes that result from ligandreceptor interactions can be obtained. This is possible because, in contrast to surface plasmon resonance (SPR) spectra, PWR spectra can be excited with both parallel and perpendicular polarized light, allowing characterization of molecular orientation within the membrane and evaluation of the anisotropy inherent in this system rather than simple changes in mass. Furthermore, PWR is much more sensitive than SPR owing to the much narrower line widths of PWR spectra, which allows quantitative measurement with a single proteolipid bilayer and nanomolar amounts of protein in the sample cell.

For our initial studies with GPCRs we chose the cloned $\mathrm{hDOR}$, which had been modified at the C-terminus with Myc and His tags. This GPCR mediates pain response in acute pain. $\mathrm{CHO}$ cells containing the hDOR were harvested and homogenized, and the membrane fraction was solubilized in an octylglucoside-containing buffer and purified by column chromatography and affinity chromatography and evaluated for purity and the ability to bind $\delta$ opioid ligands. A lipid bilayer containing $75 \mathrm{~mol} \%$ egg PC and $25 \mathrm{~mol} \%$ palmitoyl-oleoyl-phosphatidyl-glycerol (POPG) was used to form a bilayer (Figure 3A) within an orifice in a Teflon spacer on the prism. The bilayer formed is quite stable and is anchored to the orifice by an annulus of lipid solution. This bilayer readily incorporates the hDOR by introducing the detergent solubilized hDOR into the aqueous compartment under conditions that dilute the detergent to below the CMC (Figure 3A). Once the receptor is inserted into the bilayer, solutions of ligands or soluble proteins such as $\mathrm{G}$ proteins, or other molecules or ions can be added to the aqueous compartment of the PWR instrument. Insertion of the hDOR can be performed with the receptor either unoccupied or occupied by an agonist, antagonist, or inverse agonist (Figure 3A). The ligand occupied receptor (agonist, antagonist, or inverse agonist occupied) can subsequently be used to interrogate the G-protein binding processes (Figure $3 \mathrm{~B}, \mathrm{C}$ ) and in turn guanosine $5^{\prime}$-diphosphate/guanosine 5'-triphosphate (GPD/GTP) exchange (GTP $\gamma$-S binding) can be monitored in real time for changes in the PWR spectra (Figure 3B, C) using both $s$-polarized and $p$-polarized light. Fitting of the changes in spectra as a result of, for example, changes in agonist ligand concentration to a hyperbolic binding isotherm can be done to determine $\mathrm{K}_{\mathrm{D}}$ values for binding of the ligand to the hDOR. Similar studies can be made with prebound antagonist and inverse agonists, peptides, and nonpeptides. The plasmon resonance spectra depend on 3 properties of the proteolipid bilayers: the refractive index $(n)$, the absorption coefficient $(k)$, and the thickness $(t)$ of the immobilized layer. Both $s$-polarized and $p$-polarized light can be used to examine the anisotropic behavior of the system. From this process information can be obtained about the changes in structure that accompany interaction of the receptor with ligands and G-protein. For example, we have shown that incorporation of hDOR into a bilayer follows a hyperbolic curve consistent with single uniform site in the bilayers and allows calculation of mass density for closely packed molecules from which the surface area occupied per molecule can be determined. ${ }^{16}$ The value obtained $\left(1200 \AA^{2}\right)$ is consistent with the expected molecular structure of the receptor. Furthermore, as expected, $n_{p}$ values are greater than $n_{s}$ values again consistent with insertion of a cylindrically shaped receptor protein (an asymmetric structure) into a rod-shaped lipid bilayer. Finally, the thickness of the proteolipid membrane increases from $53 \AA$ before receptor insertion, to $68 \AA$ after hDOR addition. These values are consistent with known structural features of the lipid bilayer and the receptor.

Following insertion of the receptors into the bilayer, ligand binding to the receptor can be examined in detail by adding increasing concentrations of agonist (Figure 3B), antagonist, or inverse agonist ligands (Figure $3 \mathrm{C}$ ). We have examined these binding interactions in detail using PWR spectroscopy by monitoring the changes in the PWR spectra that occur on adding increasing concentrations of the ligand to the receptor. ${ }^{27}$ In these studies we have found that the binding of the ligand to the receptor leads to different changes in the spectra for $s$-polarized and $p$-polarized light consistent with an anisotropic change in structure in the binding process. Furthermore, these changes are quite different when agonists, antagonists, and an inverse agonist bind to the receptor, completely in agreement with the interpretation that each of these receptor-occupied states has a different conformation. Of interest, some peptide agonists and nonpeptide agonists show different anisotropic spectral changes suggesting a different conformation for each of these agonist-occupiedreceptor states. This observation is consistent with previous observations we have made using $\mu$ DORs modified by sitespecific mutagenesis. ${ }^{28}$

Fitting the changes in PWR spectra that occur as the concentration of ligand is increased to saturation to a hyperbolic binding isotherm can directly provide the $\mathrm{K}_{\mathrm{D}}$ values for ligand binding to the receptor. We have examined several agonists and antagonists of the hDOR and a known inverse agonist and have shown that the $\mathrm{K}_{\mathrm{D}}$ values obtained are very similar to those reported in the literature, generally using brain membrane preparations. ${ }^{27}$ We thus conclude that our receptor preparations in lipid bilayers provide a good approximation to the structural and functional properties of the receptors in living systems. 
The AAPS Journal 2006; 8 (3) Article 53 (http://www.aapsj.org).

A
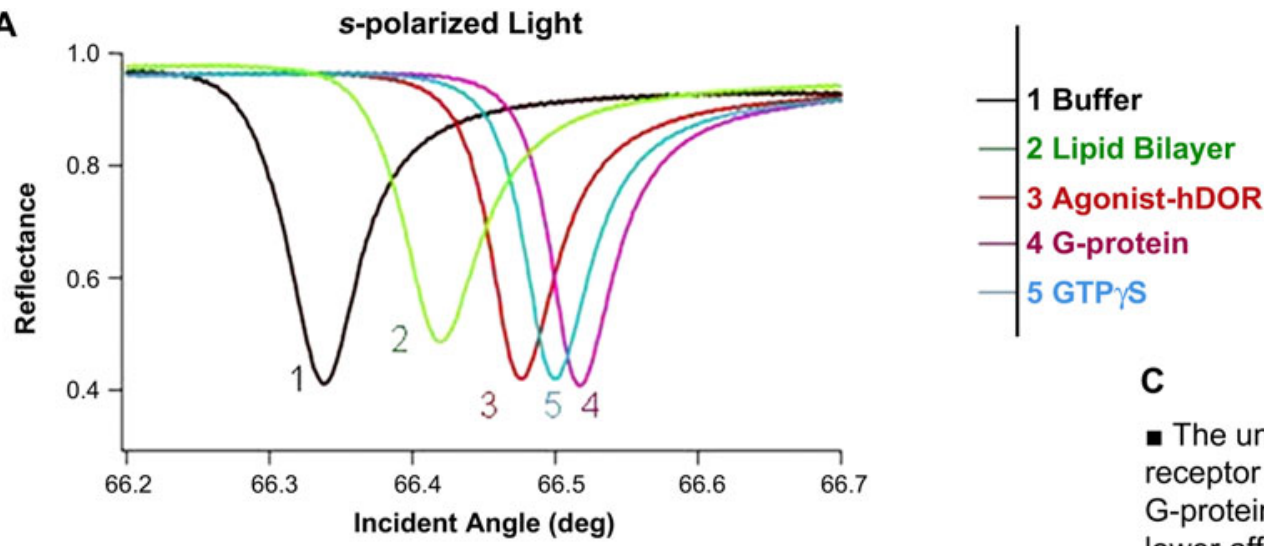

C

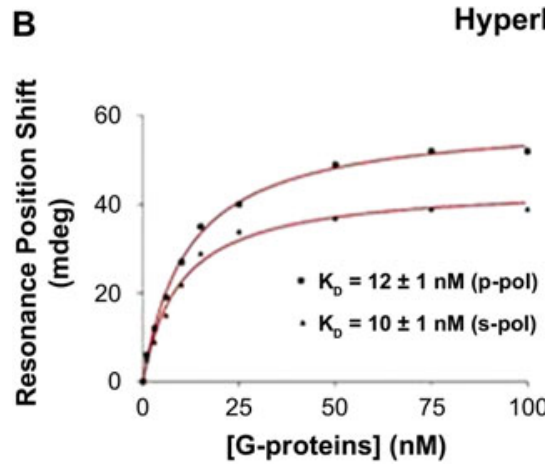

Hyperbolic Fit lower affinity $(60 \mathrm{nM})$.

- The antagonist-bound receptor has a $\mathrm{K}_{\mathrm{D}}$ of $\sim 500 \mathrm{nM}$ for the G-protein interaction.

- Inverse agonist-bound receptor doesn't bind G-protein.

- GTP $\gamma S$ effect was only seen in the agonist-bound receptor.

Figure 3. PWR equilibrium spectra following the changes of reflectance for study of G-protein receptors in lipid bilayers: (A) PWR equilibrium spectra for various experimental situations, (B) PWR binding isotherm for G-protein binding to agonist-bound DPDPEhDOR complex (left) and subsequent measurement of GTP $\gamma \mathrm{S}$ binding (right), and (C) Other observations made using PWR spectroscopy with other unoccupied or ligand-occupied hDORs.

With this in mind, we extended our studies to examine the binding of G-proteins to the incorporated hDOR and examined the PWR spectral changes that accompany the addition of the G-proteins (Figure 3B). In these experiments, the hDOR receptor was inserted into the membrane bilayers either unoccupied by a binding ligand, or occupied by an agonist, an antagonist, or an inverse agonist. We found that prebinding of a ligand to the receptor results in changes in G-protein interaction with the occupied receptor that varies with the ligand type (agonist, antagonist, or inverse agonist). This finding demonstrates that the receptor inserts into the membrane bi-directionally and thus permits exploration of processes that occur on both extracellular and intracellular membrane surfaces. This fortunate situation has allowed us to examine the consequences of the interaction of G-proteins with variously occupied receptors to provide novel insights that may provide a completely new way to do structure-biological activity relationships in drug design. We briefly discuss some of these findings below.

The $\delta$ opioid agonist (DPDPE) ${ }^{19}$-occupied receptor was inserted in the lipid bilayer and then was interrogated with a purified mixture of the predominant forms of the pertussis toxin-sensitive G-proteins from bovine brain (Calbiochem, EMD Biosciences) associated with the DOR containing
$G_{\alpha 0}, G_{\alpha i 1}, G_{\alpha i 2}$, and $G_{\alpha i 3}$ and the $\beta \gamma$ subunit complex. ${ }^{29}$ When these were incrementally added, changes in PWR spectra were observed (Figure 3B). As shown in Figure 3, saturation was obtained at higher concentrations, and again the $\mathrm{K}_{\mathrm{D}}$ value of the binding of the G-protein to the agonist occupied hDOR could be determined by fitting the data to a hyperbolic binding isotherm. As can be seen, both $s$-polarized and $p$-polarized light gave the same $\mathrm{K}_{\mathrm{D}}$ value as expected. After saturation of the receptor with the G-protein was reached, GTP $\gamma \mathrm{S}$ was added and, as before, the changes in the PWR spectra were monitored as shown in Figure 3C. The $\mathrm{K}_{\mathrm{D}}$ value for GTP $\gamma \mathrm{S}$ binding was found to be $\sim 14 \mathrm{nM}$. Note that the anisotropic spectral changes seen with GTP $\gamma \mathrm{S}$ binding were in the opposite direction as those seen for G-protein binding to the DPDPE-occupied receptor. We interpret this result to be caused by the release of the alpha subunit of the G-protein after GTP/GDP exchange. Note that the G-protein binding to the agonist-occupied receptor and the GTP $\gamma \mathrm{S}$ binding to the G-protein have $\mathrm{K}_{\mathrm{D}}$ values of similar magnitude. Similar experiments with the antagonist (naltrindole)-occupied hDOR showed that the G-protein was only weakly bound to the receptor $\left(\mathrm{K}_{\mathrm{D}} \sim 500 \mathrm{nM}\right)$, and that the GTP $\gamma$ S apparently does not bind to the G-protein in this case (data not shown). This finding is consistent with expectation, showing that these interactions reflect receptor 
biology. By directly monitoring these effects, PWR allows them to be quantified, which is very difficult to do by other methods. This has important implications for drug discovery protocols.

Of interest, unoccupied hDOR still binds the G-protein but with an intermediate affinity $(\sim 60 \mathrm{nM})$ but no GTP $\gamma \mathrm{S}$ binding was detected. Again, as expected, the inverse agonistoccupied receptor does not bind the G-protein nor is any GTP $\gamma \mathrm{S}$ binding detected. These results further validate as previously discussed (vide supra) that the hDOR assumes different structures depending on the nature of the ligand bound to it (agonist, antagonist, inverse agonist, and unoccupied receptor). This picture is quite different from that usually depicted in biochemistry or pharmacology textbooks and reviews. These 4 different conformational states appear to be essential for the proper functioning of information transduction that is used for biological function in response to changes in the environment of the cell.

If one uses the purified $G \alpha$-protein subtypes $\left(G_{\alpha 0}, G_{\alpha i 1}\right.$, $\mathrm{G}_{\alpha \mathrm{i} 2}$, and $\mathrm{G}_{\alpha \mathrm{i} 3}$ ) in combination with the $\beta \gamma$ subunits and then interrogates them with either ligand-occupied hDORs or the unliganded state, a remarkably diverse set of transduction pathways emerges (Table 5).$^{30}$ Examining first the DPDPE-bound hDOR, there is a 40-fold difference in binding of the different G-protein subtypes. Moreover there no longer is a uniformly close 1:1 correspondence between G-protein binding to the agonist-occupied receptor and GTP $\gamma \mathrm{S}$ binding. Thus, in the case of the $\mathrm{G}_{\alpha \mathrm{i} 2}$ protein, there is essentially 1 to 1 correspondence, but for the other highaffinity G-protein $G_{\alpha o}$ there is up to a 40 -fold difference in G-protein binding to the agonist-occupied receptor and GTP $\gamma \mathrm{S}$ binding. Since transduction requires both the G-protein binding event and GDP/GTP exchange, clearly the most likely transduction pathway in this case will be via the $\mathrm{G}_{\alpha \mathrm{i} 2}$ protein. Remarkably, a completely different picture emerges when examining these binding events with a nonpeptide-hDOR complex, namely, the SNC80-hDOR complex (Table 5). In this case, the G-protein, which binds most strongly to the hDOR is the $\mathrm{G}_{\alpha o}$ protein and this also has potent GTP $\gamma \mathrm{S}$ binding. On the other hand, although the $\mathrm{G}_{\alpha \mathrm{i} 2}$ protein binds strongly to the agonist-occupied DOR, a 7-fold decrease in GTP $\gamma \mathrm{S}$ binding occurs.

Also of interest is the observation that the partial agonist for the hDOR (morphine) chooses yet another G-protein, $\mathrm{G}_{\mathrm{\alpha i} 1}$ (Table 5), and all of the other G-proteins bind GTP $\gamma \mathrm{S}$ very weakly and thus are unlikely to transduce any message very well. By enabling a quantitative measure of the affinity between the receptor and G-protein subtypes, PWR spectroscopy offers a unique approach and new insights into the molecular mechanisms that may govern the efficacy of opioids. Conventional analyses by and large evaluate the influence of receptor/G-protein complexes on the affinity of ligands for the receptors; the analyses make the assumption that some predominant conformation(s) of the receptor or receptor/G-protein complexes dictate the affinity of the agonist for the receptor and, by assumption, the

Table 5. $\mathrm{K}_{\mathrm{D}}$ Values (nM) for Binding of the Different G-Protein Subtypes to the Different Liganded States of the Human $\delta$ Opioid Receptor

\begin{tabular}{|c|c|c|c|c|c|}
\hline \multirow[b]{2}{*}{ G-Protein subtype } & \multicolumn{3}{|c|}{ Agonist (DPDPE)-bound } & \multirow[b]{2}{*}{$\mathbf{G}_{\mathbf{\alpha i 2}}$} & \multirow[b]{2}{*}{$\mathbf{G}_{\mathbf{\alpha i 3}}$} \\
\hline & $\mathbf{G}_{\boldsymbol{\alpha} 0}$ & & & & \\
\hline $\mathrm{K}_{\mathrm{D}}^{\mathrm{G}-\text { protein }}(\mathrm{nM})$ & $10 \pm 1$ & \multicolumn{2}{|l|}{$300 \pm 30$} & $7 \pm 1$ & $43 \pm 5$ \\
\hline $\mathrm{K}_{\mathrm{D}}^{\mathrm{GTP}} \gamma^{\mathrm{S}}(\mathrm{nM})$ & $400 \pm 50$ & \multicolumn{2}{|l|}{$4.2 \pm 0.5$} & $9.9 \pm 0.7$ & $82 \pm 10$ \\
\hline \multicolumn{6}{|c|}{ Unliganded Receptor } \\
\hline G-Protein subtype & $\mathbf{G}_{\alpha \mathbf{0}}$ & \multicolumn{2}{|c|}{$\mathbf{G}_{\alpha \mathrm{i} 1}$} & $\mathbf{G}_{\mathrm{i \alpha i2}}$ & $\mathbf{G}_{\alpha \mathbf{i} 3}$ \\
\hline $\mathrm{K}_{\mathrm{D}}^{\mathrm{G}-\text { protein }}(\mathrm{nM})$ & $21 \pm 1.8$ & \multicolumn{2}{|l|}{$80 \pm 9$} & $585 \pm 70$ & $95 \pm 10$ \\
\hline $\mathrm{K}_{\mathrm{D}} \mathrm{GTP}^{\mathrm{S}}(\mathrm{nM})$ & $1900 \pm 200$ & \multicolumn{2}{|l|}{$*$} & $*$ & $*$ \\
\hline \multicolumn{6}{|c|}{ Partial Agonist (morphine)-bound } \\
\hline G-Protein subtype & $\mathbf{G}_{\alpha \mathbf{0}}$ & $\mathbf{G}_{\alpha \mathbf{i} 1}$ & & $\mathbf{G}_{\alpha \mathrm{i} 2}$ & $\mathbf{G}_{\alpha \mathrm{i} 3}$ \\
\hline $\mathrm{K}_{\mathrm{D}}^{\mathrm{G}-\text { protein }}(\mathrm{nM})$ & $43 \pm 5$ & $33 \pm 8$ & & $310 \pm 27$ & $17 \pm 3$ \\
\hline $\mathrm{K}_{\mathrm{D}} \mathrm{GTP}^{\mathrm{S}}(\mathrm{nM})$ & $925 \pm 125$ & $93 \pm 11$ & & $1650 \pm 130$ & $910 \pm 142$ \\
\hline \multicolumn{6}{|c|}{ Agonist (SNC 80)-bound } \\
\hline G-Protein subtype & $\mathbf{G}_{\alpha \mathbf{0}}$ & $\mathbf{G}_{\alpha \mathrm{i} 1}$ & & $\mathrm{G}_{\alpha \mathrm{i} 2}$ & $\mathbf{G}_{\alpha \mathbf{i} 3}$ \\
\hline $\mathrm{K}_{\mathrm{D}}^{\mathrm{G}-\text { protein }}(\mathrm{nM})$ & $5 \pm 0.5$ & $215 \pm 33$ & $209 \pm 33$ & $14 \pm 1.1$ & $19 \pm 2$ \\
\hline $\mathrm{K}_{\mathrm{D}} \mathrm{GTP}_{\gamma} \mathrm{S}(\mathrm{nM})$ & $10 \pm 1.8$ & $2.2 \pm 0.4$ & $2.4 \pm 0.3$ & $97 \pm 14$ & $24 \pm 3$ \\
\hline
\end{tabular}

*No G-protein activation up to $5 \mu \mathrm{M}$ of GTP $\gamma \mathrm{S}$ 


\section{The AAPS Journal 2006; 8 (3) Article 53 (http://www.aapsj.org).}

ensuing efficacy for a particular signaling pathway. The PWR analysis instead evaluates the dynamic interactions between the receptor and G-proteins as a result of agonist occupancy. The data presented here show that the full agonists, DPDPE and SNC80, and the partial agonist, morphine, confer very different profiles on the hDOR for G-protein binding and subsequent GTP exchange. One interpretation of the current data is that the more efficiently an agonist can induce G-protein binding and GTP exchange, and furthermore coupling to multiple G-protein subtypes, the more efficacious the agonist would be at that receptor. The affinity of hDOR for $\mathrm{G}_{\alpha \mathrm{o}}, \mathrm{G}_{\alpha \mathrm{i} 2}$, and $\mathrm{G}_{\alpha \mathrm{i} 3}$ upon SNC80 occupancy versus the affinity of hDOR for $\mathrm{G}_{\alpha i 3}$ only and low affinity for GTP when occupied by morphine is a case in point.

The above observations may explain the often-suggested idea of apparent "subtypes" of $\delta$ opioid receptors. Rather, our studies suggest that these different "subtypes" may result from the different transduction pathways induced by the ligand as defined by relative efficacy of the ligands in different tissues. Actually, since different pathological pain disease states may be a result of different phenotypes, the nature of the ligand for the GPCR may result in the emergence of a specific phenotypic response depending on the nature of the ligand. If this is the case, then PWR spectroscopy provides a unique and powerful assay system for developing drug ligands that can address specific pathological pain conditions.

We also have examined whether the interactions of the ligands with the receptor are modulated or different when individual G-proteins are present. That is, is there a reciprocal effect of the G-protein binding to the receptor on the affinity of the ligand for the receptor? In general we have found that the G-proteins have no effect on antagonist and inverse-agonist binding, which is consistent with current conclusions from classical binding and second messenger studies. On the other hand, in the presence of G-proteins, agonists such as DPDPE and SNC80 bind with 6- to 8-fold higher affinity to the hDOR than when no G-proteins are present, demonstrating that in the absence of G-proteins the hDOR is in a lower affinity state than when in their presence. This observation is in agreement with a model in which G-protein promotes a high affinity state of the receptor for agonists.

Finally, we have examined the binding of the $\alpha$ and $\beta \gamma$ subunits of the hDOR when it is occupied with agonists such as DPDPE and SNC80 and the partial agonist morphine. Surprisingly, we found in all cases that the highest affinity $\alpha$ subunit $\left(G_{\alpha i 2}\right.$ for DPDPE-occupied receptor, $G_{\alpha o}$ for the SNC80-occupied receptor, and $\mathrm{G}_{\alpha \mathrm{i} 1}$ for the morphineoccupied receptor) bound less tightly by a factor of 5 to 7 than the $\beta \gamma$ subunit. These data suggest that both the $\mathrm{G}_{\alpha}$ and the $\beta \gamma$ subunits consist of intrinsic structures that allow them to interact with the hDOR independently of each other. The affinity of the $\beta \gamma$ subunit for the hDOR is consistent with the proposed function of this subunit complex whose association with the receptor is essential for initiating receptor internalization. The current model proposes that the G-protein trimeric complexes have the best structural characteristics for interacting with a G-protein coupled receptor. Thus, the $\beta \gamma$ subunit is critical, by complexing with the alpha subunits to form the trimeric G-protein complex, to facilitate the G-protein's affinity for hDOR. Experimental evidence in the literature suggests that the beta/gamma subunits serve as a GTPase activating protein (GAP) whose function is to promote the formation of the functional G-protein trimers. The data from the PWR analysis support this hypothesis and suggest further that the $\beta \gamma$ subunits contribute significantly to the G protein's binding to the agonist-occupied receptor.

These and others studies demonstrate that PWR spectroscopy provides a powerful new tool for investigating proteolipid structural changes involving GPCRs in various aspects of transmembrane signaling including binding of ligands to the receptor, the interactions of G-proteins and G-protein subunits with the receptor in various receptor states, and GTP $\gamma \mathrm{S}$ binding to the G-proteins when the GPCRs are unoccupied or occupied with agonists, antagonists, or inverse-agonists. Of note, all these experiments can be done without the need for radiolabels, fluorescent labels, or structural modifications of the receptor by mutagenesis, all of which can lead to artifacts that are difficult to determine. On the other hand, it might be argued that our studies do not correspond to the actual biological system, which is much more complicated. Whereas there is certainly some validity in such arguments and caution must be exercised in interpreting such "model studies" in terms of actual biological processes, our studies thus far have indicated that in terms of binding $K_{D}$ values and other parameters that can be examined by PWR spectroscopy, and compared with other biochemical and biophysical methods that are more traditionally considered as "biological systems" (membrane preparation and whole cells), we have obtained very good agreement between the latter studies and those obtained with our reconstitution methods and using PWR spectroscopy. Furthermore, there is a long and successful history of reconstitution of membrane proteins into lipid bilayer vesicles. There is no reason to think that reconstitution into a solid-supported planar bilayer would be any less successful. We conclude that it is reasonable to suggest that PWR spectroscopy should be useful for examining further aspects of transmembrane signaling such as the effects of other modulatory proteins that are involved in GPCR signaling, including clathrins, $\beta$-arrestins, kinases, phosphatases, and ion channels. In addition we hope to be able to address directly the significance (or not) of 
The AAPS Journal 2006; 8 (3) Article 53 (http://www.aapsj.org).

homomeric and heteromeric GPCR dimerization in signal transduction as well as the role of lipid structure, lipid rafts, and other structural modulators of the lipid bilayer that might be important in modulation of GPCR signal transduction pathways.

\section{CONCLUSIONS}

Clearly the developments stemming from genomics and proteomics for examining systemic changes that occur during the development of diseases such as neuropathic pain, cancer, and diabetes is demanding a reevaluation of our past approaches to drug development. In this context, new biophysics methods such as PWR spectroscopy are providing important physical tools for examining more carefully the mechanisms involved in such critical biological activities as transmembrane signaling, protein-ligand interactions, and protein-protein interactions.

In terms of optimized drug discovery for disease, clearly the application of current strategies of parallel or combinatorial synthesis and high throughput assays, have not provided many new insights into how best to address drug design and discovery. It is very clear that nervous system changes and cellular changes that occur in the setting of injury and disease need to be examined from the viewpoint of how therapy can address these changes directly and not simply modulate or ameliorate symptoms of the disease state. It is critical to realize that the target for treatment has changed from the "normal" state, and hence these system level adaptations must be considered in drug design and treatment strategies. Drugs need to be designed for optimal activity in the disease states, so that they can overcome and/or ameliorate adaptations of the cellular and or nervous system. Of interest, as we have shown here, design will often involve ligands with activities at more than one "biological" target. The development of concepts of overlapping pharmacophores, multivalent ligands, and systems-based design are critical new approaches that are in need of new ideas and new paradigms.

\section{ACKNOWLEDGMENTS}

This study was supported by grants from the United States Public Health Service, GM 59630 (GT and ZS), and National Institute of Drug Abuse, DA 06284 (VJH), DA 1339 (VJH), and DA 12394 (FP), which are gratefully acknowledged.

\section{REFERENCES}

1. Hruby VJ. Designing peptide receptor agonists and antagonists. Nat Rev Drug Discov. 2002;1:847-858.

2. Ossipov MH, Lai J, Porreca F. Mechanisms of experimental neuropathic pain: Integration from animal models. In: McMahon S,
Koltzenburg M, eds. Wall and Melzack's Textbook of Pain. 5th ed. New York, NY: Elsevier; 2005:929-946.

3. Ossipov MH, Porreca F. Challenges in the development of novel treatment strategies for neuropathic pain. NeuroRx. 2005;2:650-661.

4. Vera-Portocarrero LP, Zhang ET, Ossipov MH, et al. Descending facilitation from the rostral ventromedial medulla maintains nerve injury-induced central sensitization. Neuroscience. In press.

5. Ossipov MH, Porreca F. Descending modulation of pain. In: Merskey H, Loeser JD, Dubner R, eds. The Paths of Pain 1975-2005. Seattle, WA: IASP Press; 2005:117-130.

6. Xie JY, Herman SD, Stiller CO, et al. Cholecystokinin in the rostral ventromedial medulla mediates opioid-induced hyperalgesia and antinociceptive tolerance. J Neurosci. 2005;25:409-416.

7. King T, Ossipov MH, Vanderah TW, Porreca F, Lai J. Is paradoxical pain induced by sustained opioid exposure an underlying mechanism of opioid antinociceptive tolerance? Neurosignals. 2005;14:194-205.

8. Heinricher MM, Neubert MJ. Neural basis for the hyperalgesic action of cholecystokinin in the rostral ventromedial medulla. $J$ Neurophysiol. 2004;92:1982-1989.

9. Wilcox GL, Stone LS, Ossipov MH, Lai J, Porreca F. Pharmacology of pain and analgesia. In: Pappagallo M, ed. The Neurologic Basis of Pain. New York, NY: McGraw-Hill; 2004:31-52.

10. Hruby VJ, Meyer J-P. Chemical synthesis of peptides. In: Hecht SM, ed. Bioorganic Chemistry: Peptides and Proteins. New York, NY: Oxford University Press; 1998:27-64.

11. Misicka A, Lipkowski AW, Horvath R, et al. Topographical requirements for $\delta$ opioid ligands: common structural features of dermenkephalin and deltorphin. Life Sci. 1992;51:1025-1032.

12. Kramer TH, Davis P, Hruby VJ, Burks TF, Porreca F. In vitro potency, affinity and agonist efficacy of highly selective $\delta$ opioid receptor ligands. J Pharmacol Exp Ther. 1993;266:577-584.

13. Salamon Z, Macleod HA, Tollin G. Coupled plasmon-waveguide resonators: a new spectroscopic tool for probing proteolipid film structure and properties. Biophys J. 1997;73:2791-2797.

14. Salamon Z, Tollin G. Plasmon resonance spectroscopy: probing molecular interactions at surfaces and interfaces. Spectroscopy. 2005;15:161-175.

15. Tollin G, Salamon Z, Hruby VJ. Techniques: plasmon-waveguide resonance (PWR) spectroscopy as a tool to study ligand-GPCR interactions. Trends Pharmacol Sci. 2003;24:655-659.

16. Salamon Z, Cowell S, Varga E, Yamamura HI, Hruby VJ, Tollin G. Plasmon resonance studies of agonist/antagonist binding to the human $\delta$-opioid receptor: new structural insights into receptor-ligand interactions. Biophys J. 2000;79:2463-2474.

17. Alves ID, Salamon Z, Varga E, Yamamura HI, Tollin G, Hruby VJ. Direct observation of G-protein binding to the human $\delta$-opioid receptor using plasmon-waveguide resonance spectroscopy. J Biol Chem. 2003;278:48890-48897.

18. Slaninová J, Knapp RJ, Wu J, et al. Opioid receptor binding properties of analgesic analogues of cholecystokinin octapeptide. Eur J Pharmacol. 1991;200:195-198.

19. Mosberg HI, Hurst R, Hruby VJ, et al. Bis-penicillamine enkephalins possess highly improved specificity toward $\delta$ opioid receptors. Proc Natl Acad Sci USA. 1983;80:5871-5874.

20. Hruby VJ, Fang SN, Kramer TH. Analogues of cholecystokinin $26-33$ selective for B-type CCK receptors possess $\delta$ opioid receptor agonist activity in vitro and in vivo: Evidence for similarities in CCK-B 


\section{The AAPS Journal 2006; 8 (3) Article 53 (http://www.aapsj.org).}

and $\delta$ opioid receptor requirements. In: Hodges RS, Smith JA, eds. Peptides: Chemistry, Structure and Biology. Proceedings of the 13th American Peptide Symposium; June 20-25, 1993; Alberta, Canada. Leiden, The Netherlands: ESCOM Publishers; 1994:669-671.

21. Nikiforovich GV, Hruby VJ, Prakash O, Gehrig CA. Topographical requirements for $\delta$-selective opioid peptides. Biopolymers. 1991;31:941-955.

22. Hruby VJ, Fang SN, Knapp R, Kazmierski WM, Lui GK, Yamamura HI. Cholecystokinin analogues with high affinity and selectivity for brain membrane receptors. Int J Pept Protein Res. 1990;35:566-573.

23. Hruby VJ. Conformational restrictions of biologically active peptides via amino acid side chain groups. Life Sci. 1982;31:189-199.

24. Hruby VJ, Al-Obeidi F, Kazmierski WM. Emerging approaches in the molecular design of receptor selective peptide ligands:

conformational, topographical and dynamic considerations. Biochem J. 1990;268:249-262.

25. Bartosz-Bechowski H, Davis P, Slaninova J, et al. Cyclic enkephalin analogues that are hybrids of DPDPE-related peptides and Met-enkephalin-Arg-Gly-Leu: prohormone analogues that retain good potency and selectivity for $\delta$ opioid receptors. $J$ Pept Res. 1999;53:329-336.

26. Hruby VJ, Bartosz-Bechowski H, Davis P, et al. Cyclic enkephalin analogues with exceptional potency and selectivity for $\delta$-opioid receptors. J Med Chem. 1997;40:3957-3962.

27. Alves ID, Cowell SM, Salamon Z, Devanathan S, Tollin G, Hruby VJ. Different structural states of the proteolipid membrane are produced by ligand binding to the human $\delta$-opioid receptor as shown by plasmonwaveguide resonance spectroscopy. Mol Pharmacol.

2004;65:1248-1257.

28. Hosohata Y, Varga EV, Stropova D, et al. Mutation W284L of the human $\delta$ opioid receptor reveals agonist specific conformational mechanisms of G-protein activation. Life Sci. 2001;68:2233-2242.

29. Alves ID, Salamon Z, Varga E, Yamamura HI, Tollin G, Hruby VJ. Direct observation of G-protein binding to the human $\delta$-opioid receptor using plasmon-waveguide resonance spectroscopy. J Biol Chem. 2003;278:48890-48897.

30. Alves ID, Ciano KA, Boguslavsky V, et al. Selectivity, cooperativity, and reciprocity in the interactions between the $\delta$-opioid receptor, its ligands, and G-proteins. J Biol Chem. 2004;279:44673-44682. 